\title{
Development of Powerhouse Using Fresnel lens
}

\author{
Nawar Saif Al-Dohani ${ }^{1}$, Nagaraj S. Nayak ${ }^{1 *}$, Anarghya A. ${ }^{2}$ and Abhishek V. N. ${ }^{3}$ \\ ${ }^{1}$ Caledonian College of Engineering, Seeb, Sultanate of Oman \\ ${ }^{2}$ National Institute of Technology Karnataka, Surathkal, India \\ ${ }^{3}$ Toyota Boshoku Automotive India Pvt. Ltd., Bangalore, India
}

\begin{abstract}
Solar energy is an alternative source of renewable energy. Sultanate of Oman government showed initiation on utilization of solar energy for domestic and industrial applications. Fresnel lens is one of the methods to collect maximum energy by gathering heat of the sun in the concentrated form (using solar collectors). Earlier research work discloses that Fresnel lens gave better result in terms of power output and produces lower heat loss as compared to linear-parabolic solar collectors. In this work, development of a proto Fresnel lens power house was made to generate electricity. The focused heat from Fresnel lens was used to heat the molten salt in a heat exchanger to produce the steam. The generated steam was used to rotate the steam engine coupled to a generator. In the current work, a maximum power of $30 \mathrm{~W}$ was produced. In addition, comparative study was carried out regarding solar salts and heat exchanger materials to understand the Fresnel powerhouse performance. Overall the present study gave valuable information regarding usage of Fresnel lens for electricity generation in Oman.
\end{abstract}

Keywords: Solar energy, Fresnel lens, solar salt, steam engine, electricity

\section{Introduction}

Renewable energy is a type of energy which can be acquired from natural resources that can be constantly recharged. Sultanate of Oman geographical location helps to develop the hot climatic conditions throughout the year and every city in Oman can make it an ideal location for exploitation of solar energy to produce electricity or used for water heating systems. However, recent study demonstrated Oman is not using solar energy effectively. In this context, Oman government has initiated on effective utilization of solar energy in residential and industrial areas. Research work is underway to collect the solar energy in effective manner. Normally, solar collector is used to collect the solar heat and there are different types of collectors, namely power tower, dish sterling, parabolic trough and Fresnel reflector. These approaches were executed in different parts of the world and generated energy in terms of MW. Facao and Oliveira (2010) studied the replica of a linier Fresnel solar collector and work demonstrated the optical and thermal performances of a new trapezoidal cavity for a small linear Fresnel receiver. In their work, the Ray -tracing simulation and computational fluid dynamics (CFD) approach was used. In addition,

\footnotetext{
* Corresponding author: nagarajsnayak@gmail.com
} 
Mahmoud and Mohamed (2011) carried out humidification and dehumidification experiments on water desalination with Fresnel lens. Lin et al (2013) carried out theoretical and experimental analysis on linear Fresnel lens reflector with $\mathrm{V}$-shaped cavity receiver. The study showed linear Fresnel lens reflector technology is viewed as a most promising approach to focus the solar power. Zhao et al (2014) studied the thermal performance of the Fresnel lens using different receivers and the study demonstrated that Fresnel lens solar collector could be extensively used in many fields for energy generation. Kumar and Shunmugalatha (2014) developed a proto model of Fresnel power house with solar salt and their study gave good information on implementation of Fresnel power plant in India. In addition, Meraj Rajaee and Seyed Mahamad (2015) proposed a unique photovoltaic solar cell system that consists of semi-Fresnel lens convergent structure and a novel two axis sun tracking module to enhance the efficiency of solar cell by using less cell area and energy losses. Udawant R R et al (2016) studied the performance of Fresnel lens solar concentrator with continuous fluid flow and steam flow test methods. The study revealed that Fresnel lens Solar Concentrator system has a very good potential in generation of low pressure steam.

Thus, from the literature reviews it is confirmed that Fresnel lens collectors are important to extract the sun energy. Accordingly, in this work a prototype Fresnel lens powerhouse was developed and its performance with regard to solar salts and heat exchanger materials was studied. The outcome of the present work could be useful to implement large scale Fresnel power house in Sultanate of Oman to overcome the energy crisis.

\section{Fresnel lens powerhouse}

\subsection{Linear Fresnel lens}

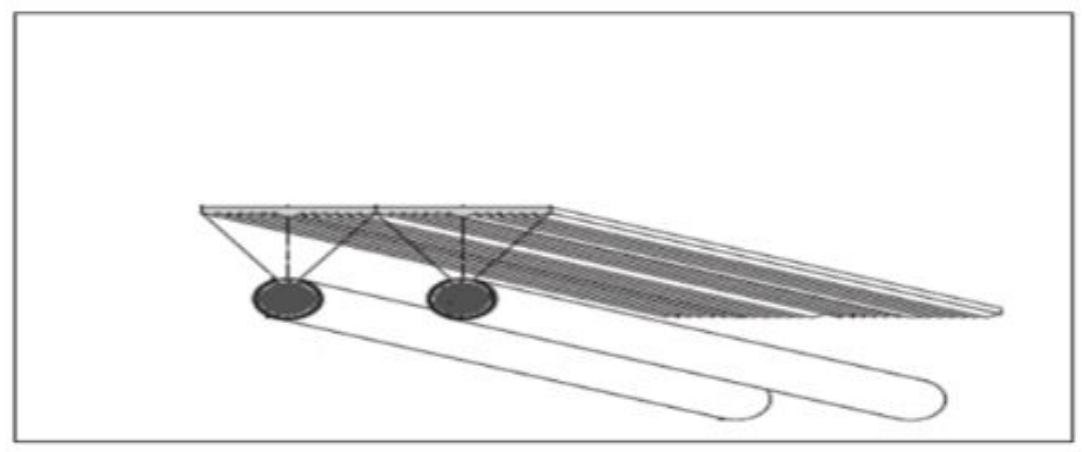

Fig. 1. Solar rays focused on tube from Linear Fresnel lens (Kumar, 2014)

Linear Fresnel lens solar collector is a non-imaging lens and is designed to forward all the solar rays on absorber. Fresnel lens is typically designed with a very short focal length, which is considered as simplified form of conventional lens. Mass and volume of material required for fabricating a Fresnel lens will be less than that the conventional lens. Hence, the cost of Fresnel lens is generally less than a conventional lens.

\subsection{Power of focal length and spot intensity of solar radiation}

In general, the focal length, $f$, of the lens is defined as distance between the lens and focal point on the object. The focal length is calculated from 


$$
\mathrm{f}=\frac{\mathrm{s}_{1}}{1-\frac{1}{\mathrm{~m}}}
$$

Where sland $\mathrm{m}$ are the distance between the Fresnel lens and receiver, and magnification factor of the lens respectively.

The power of focal length determines the effectiveness of lens and is calculated on the basis of focal length and diameter of lens. i.e., power of focal length, $\mathrm{F}$ is

$$
\mathrm{F}=\frac{\mathrm{f}}{\mathrm{D}_{\text {lens }}}
$$

Where, D lens is the diameter of the Fresnel lens.

In addition, heat received from the Fresnel lens is calculated from solar spot intensity and area of Fresnel lens.

$$
\mathrm{Q}=\mathrm{A} \cdot \mathrm{I}_{\text {spot }} \text {. }
$$

The solar spot intensity is directly related intensity of solar radiation and power of focal length. Equation 4 is used to calculate the solar spot intensity.

$$
\mathrm{F}^{2} \cdot \mathrm{I}_{\text {spot }}=\left(\frac{\mathrm{L}}{\mathrm{R}_{\text {sun }}}\right)^{2} \cdot \mathrm{I}_{0}
$$

Where $F$ is power of the focal length in Watt, Ispot is the spot intensity in W/m2, L is the length between sun to earth in $\mathrm{m}, \mathrm{I} 0$ is the solar intensity in $\mathrm{W} / \mathrm{m} 2$ and Rsun is the sun radius, $m$.

\subsection{Solar Salt Mixture}

Solar thermal power plants are the key technology for generating electricity. In this context, thermal energy storage (TES) materials will able to meet the intermediate power capacity. Hence, molten salts are attractive storage materials because they have advantages in terms of high heat capacity, high density, high thermal stability, relatively low cost and low vapour pressure. One major problem with molten salts is it freezes during the operation. The freezing of molten salt is prevented from heat exchanger or storage tanks approach via auxiliary heating systems. Nowadays, salt mixtures with low melting temperature is developed. However, at high temperatures, the salt stabilities and corrosion aspects play a major role.

Nowadays, non-eutectic salt mixture of $60 \%$ sodium nitrate and $40 \%$ potassium nitrate is typically used in thermal power plants and this mixture is commonly called Solar Salt.

\subsection{Heat exchanger}

In the present work, heat exchanger was developed to overcome the freezing of eutectic salt mixture, figure 2 . The concept of heat exchange such that tube side water is flowing and shell side is filled with solar salt. The solar heat is transferred to the heat exchanger from the focal point of Fresnel lens and it melts the molten salt and transfers heat to the water. Thus, steam is generated and is used to rotate the steam engine.

The essential quantity of mixer salt required to generate a steam from the heat exchanger is calculated from

$$
\mathrm{Q}=\mathrm{m}_{\mathrm{o}} \times \mathrm{hfg},
$$

Where $\mathrm{Q}$ is amount of heat received from Fresnel lens, $\mathrm{m}$ is mass of salt and hfg is the latent heat of fusion for solar salt.

With the help of energy balance, the required quantity of heat needed to generate the steam is evaluated i.e., the heat taken by water is equal to the heat lost by salt. Similarly, the size of heat exchanger is determined from equation 6 .

$$
\mathrm{Q}=\mathrm{UA} \Delta \mathrm{T}
$$


Where $U$ and $\Delta T$ are the overall heat transfer coefficient in $\mathrm{W} / \mathrm{m} 2 \mathrm{~K}$, and the change of temperature across the heat exchanger respectively.

In addition, in the current work external auxiliary heating unit is coupled to heat exchanger to avoid the freezing of solar salt.

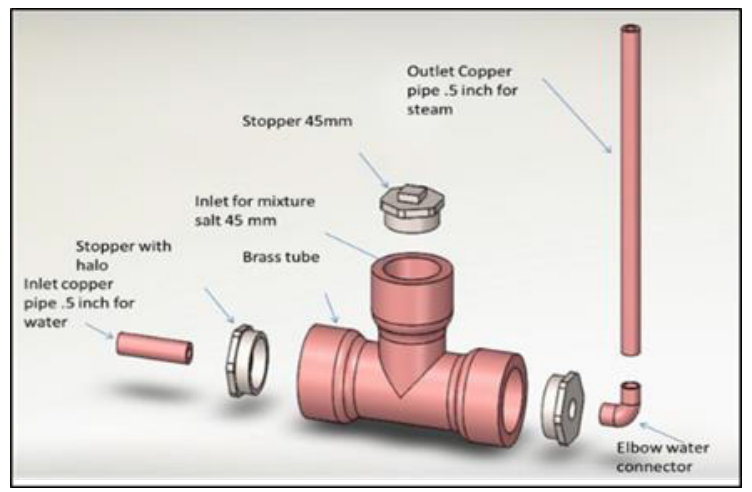

Fig. 2. Parts of eutectic salt heat exchanger

\section{Experimental methodology}

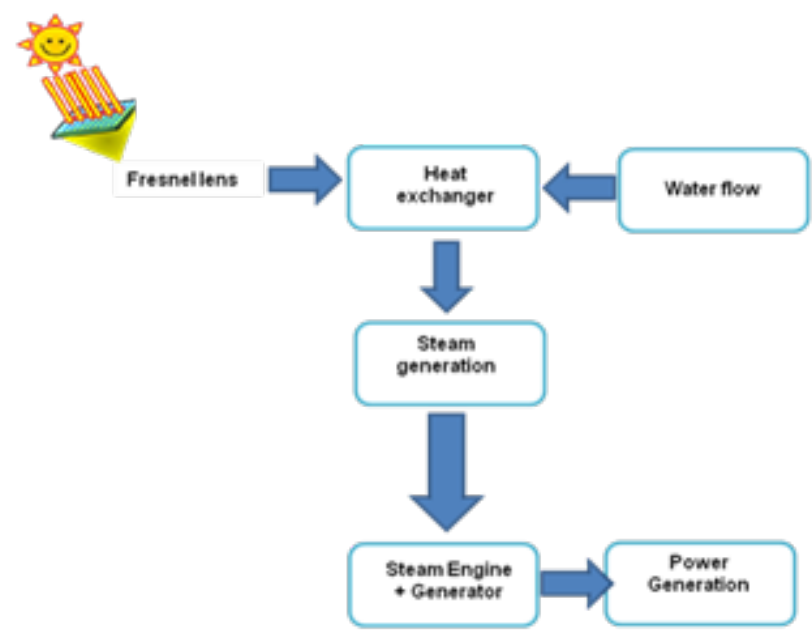

Fig. 3. Block diagram of Fresnel power house

Fig. 3 represent the block diagram of Fresnel powerhouse. Fresnel lens focused the solar rays on the heat exchanger and transfers the heat to the solar salt. Solar salt stores the thermal energy and releases this energy to covert water to steam. The generated steam passes through steam engine coupled with generator. The generated DC current is used to glow the bulb. Fig. 4 explains the experimental set-up of proto model of developed Fresnel powerhouse. 


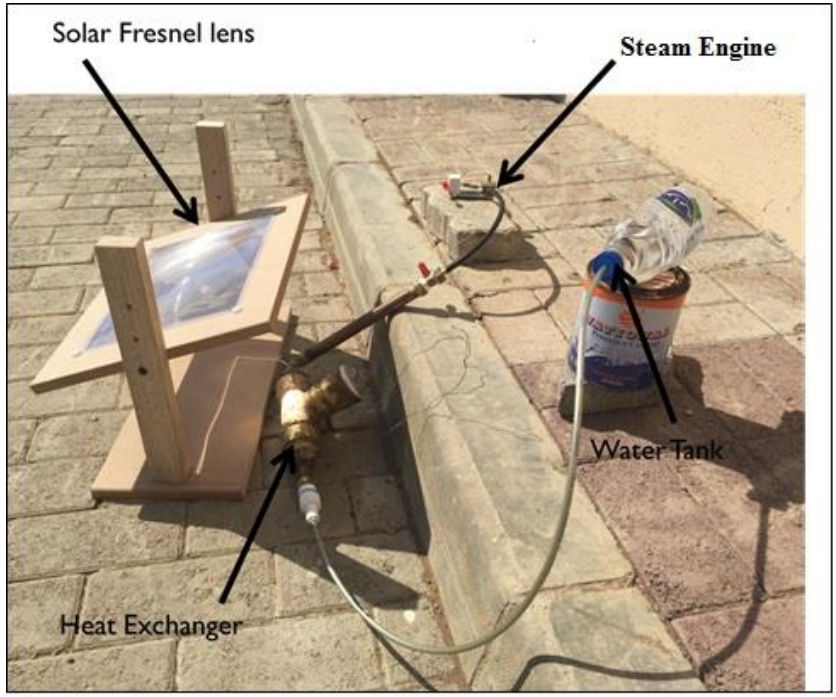

Fig. 4. Experimental set up of proto Fresnel lens powerhouse

\section{Results and discussion}

\subsection{Solar intensity}

In the beginning, calculation of solar intensity is made to find the intensity of the solar radiation in Oman. Theoretical calculations showed an average solar intensity of 650-750 $\mathrm{W} / \mathrm{m} 2$ in Oman in the month of November. To verify the theoretical results, solar intensity data were recorded from November 22-25, 2016. The experimental results indicated a maximum solar intensity of $725 \mathrm{~W} / \mathrm{m} 2$ at $12-1 \mathrm{PM}$, see Fig. 5.

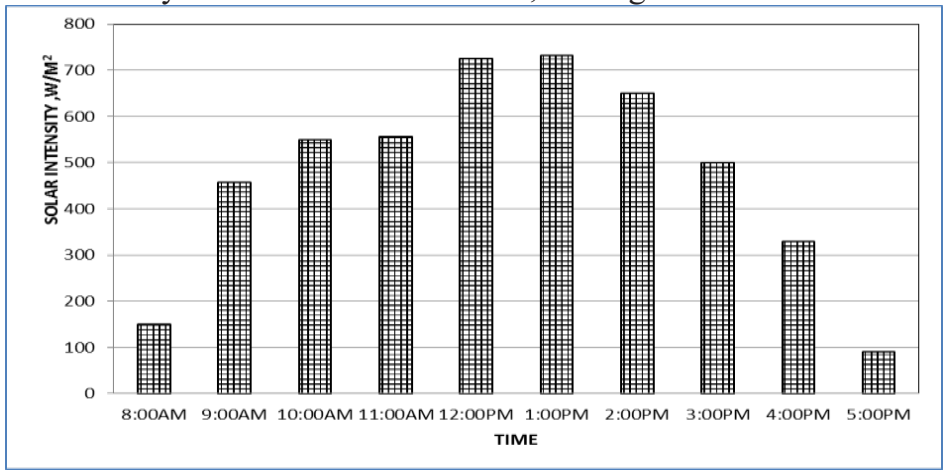

Fig. 5. Solar intensity Dated 22nd November 2016

\subsection{Performance study with KNO3 and Mixtures of KNO3 + NaNO3 salt}

At the beginning, the study has been carried out with the use of KNO3 salt and later with the mixtures of $\mathrm{KNO} 3+\mathrm{NaNO} 3$ salt in the heat exchanger. For both the cases, power developed by the steam engine is calculated from voltage and current relation. Figure 6 indicates the power output of the generator using KNO3 salt and mixtures solar KNO3 + NaNO3 salt. Similarly, Fig. 7 explains the steam temperature variation with time for 
KNO3 salt and mixtures of $\mathrm{KNO} 3+\mathrm{NaNO} 3$ salt. From the result it confirms that mixture salt gives best performance of output power developed $0.8 \mathrm{~W}$. This value is very small due to the low solar intensity and less flow of water inside the pipe and the quantity of steam generated is less. From the study it is confirmed that mixing $60 \%$ of potassium nitrate and $40 \%$ of sodium nitrate gave high temperature for the steam as compared to single salt (KNO3). The technical reason is that freezing point of the mixture salt is below $140 \mathrm{oC}$, and it helps to increase the thermal storage capacity of the salt for longer duration. In addition, it improves the heat transfer and minimizes the salt volume. Hence, in the later part of experiments mixture salt of $\mathrm{KNO} 3+\mathrm{NaNO} 3$ is used.

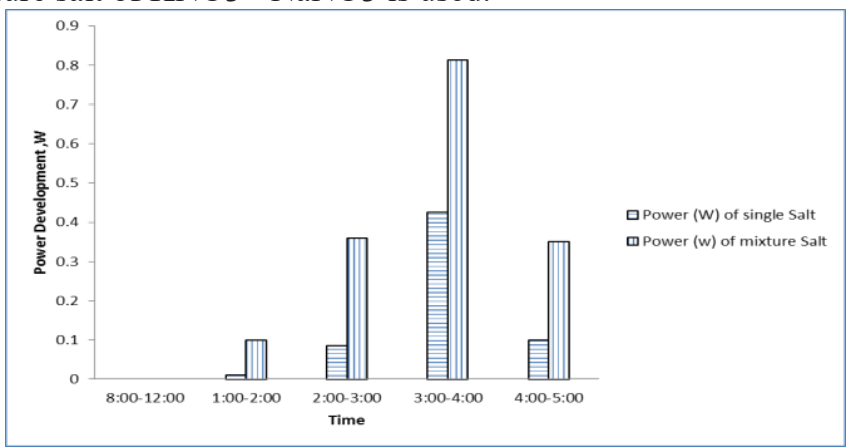

Fig. 6. Comparison of power development with $\mathrm{KNO} 3$ salt and mixture salt $\left(\mathrm{KNO}_{3}+\mathrm{NaNO}_{3}\right)$

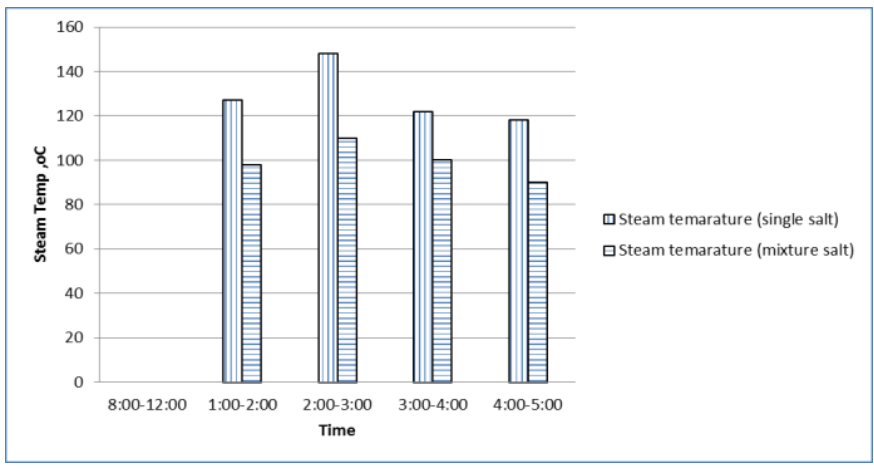

Fig. 7. Comparison of power development with $\mathrm{KNO} 3$ salt and mixture salt $(\mathrm{KNO} 3+\mathrm{NaNO} 3)$

\subsection{Significance of engine speed on power development}

The significance of engine speed on the power development is discussed in Fig. 8. The speed of the turbine at the beginning is $60 \mathrm{rpm}$ and then increased to $160 \mathrm{rpm}$. The observed maximum power across generator is $0.8 \mathrm{~W}$. From the result, it is confirmed that output power is very low to switch $\mathrm{ON}$ the bulb due to low solar intensity on the test day and it led to low steam generation to drive the turbine. 


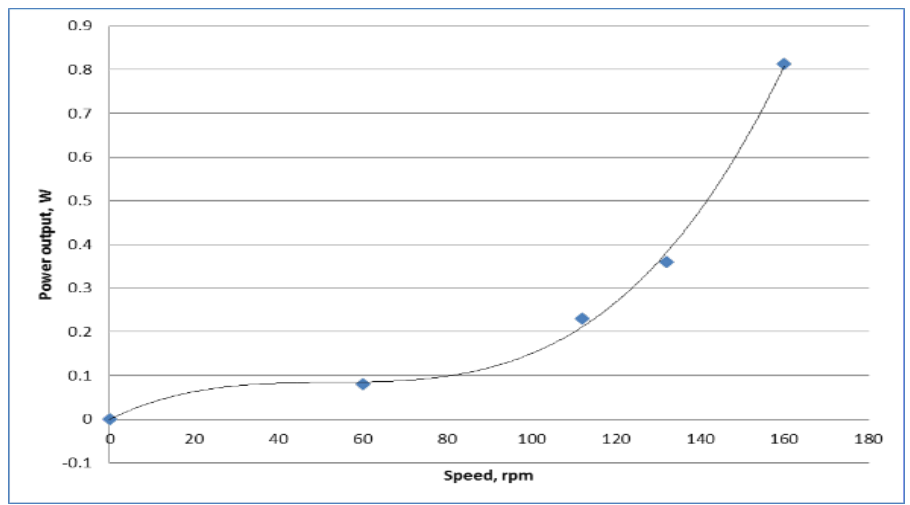

Fig. 8. Power variation with turbine speed -Solar mixture salt $(\mathrm{KNO} 3+\mathrm{NaNO} 3)$

To improve the steam generation quantity, heat exchanger design is modified and is discussed in the next section.

\subsection{Study with heat exchanger}

In the current work, shell and tube side dimensions are modified to improve the performance of heat exchanger. Also, the performance study has been carried out with brass and cast iron materials at the shell side. Due to low solar intensity, induction heater is coupled to the heat exchanger to melt the solar thermal salt. Fig. 9 indicates the power output comparison of the Fresnel powerhouse for two types of heat exchangers (shell made with cast iron and brass materials). Similarly, variation of steam temperature with cast iron and brass heat exchangers is showed in Fig. 10. From the results, it is confirmed that brass material gave best performance of $30 \mathrm{~W}$ output power and the steam outlet temperature of $160 \mathrm{oC}$ as against the cast iron heat exchanger developed $134 \mathrm{o} \mathrm{C}$ with the same input conditions. So, the above study results revealed that corrosion resistant good quality brass material would be an ideal choice at shell side of the heat exchanger and corrosion resistant copper material at the tube side of the heat exchanger to enhance the performance of Fresnel lens powerhouse.

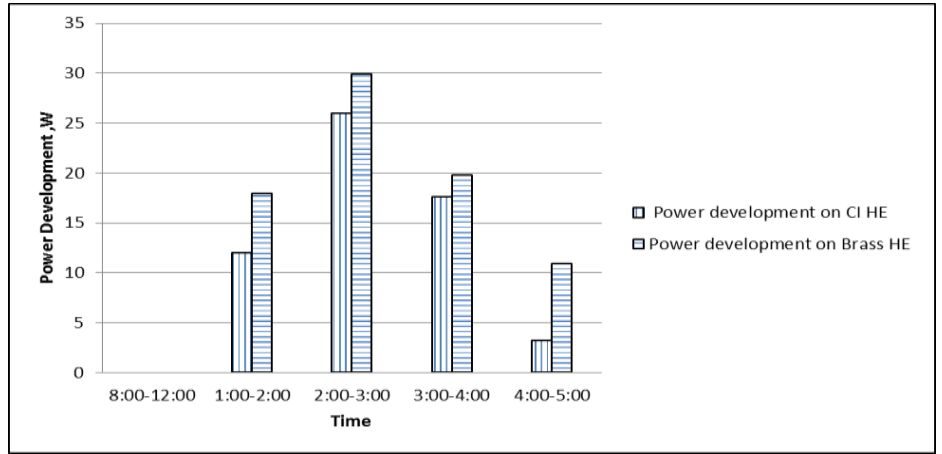

Fig. 9. Power variations with Time (Cast iron and Brass as a material for the heat exchanger) 


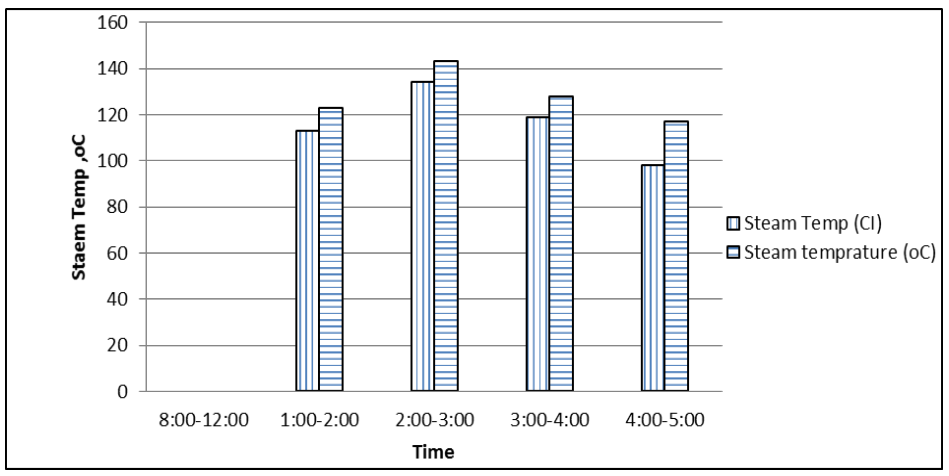

Fig. 10. Steam temperature variations with time (Cast iron and Brass as a material for the heat exchanger)

In addition, complete assembly of proto Fresnel powerhouse is studied under high intensity solar radiation. Figure 11highlights the significance of turbine speed on the developed power. A maximum power output value of $30 \mathrm{~W}$ is achieved in the afternoon session and the corresponding turbine speed is $1832 \mathrm{rpm}$. From the graph, it is confirmed that the trend of the curve is in line with fan law relationship of power (varies polynomial with an exponent of three for rotational speed). Overall, the present study gave valuable thoughts on usage of solar thermal salt in Fresnel powerhouse development. It minimized the size of heat exchanger with improved heat transfer and higher thermal energy storage capacity.

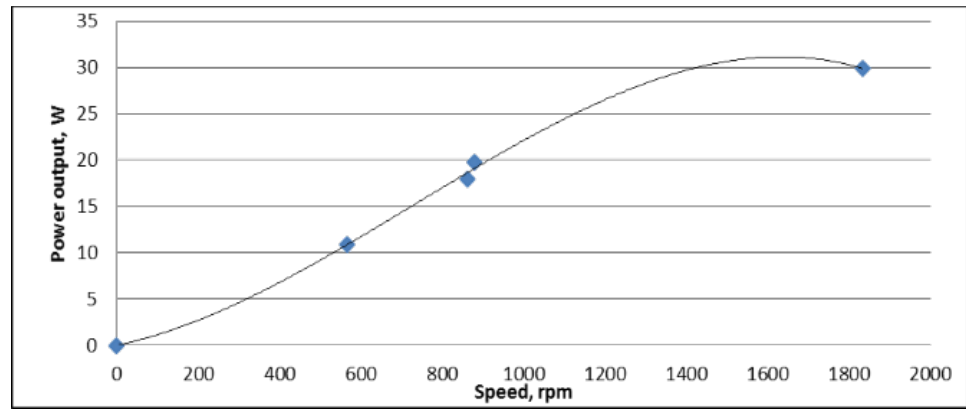

Fig. 11. Power variations with turbine speed

\section{Conclusions}

In the present work, detailed study was carried out for the development of proto Fresnel lens power house. Overall this work gave valuable information on usage of Fresnel power house in Oman to overcome the energy crisis. The following are the outcomes of the study:

- The proto model Fresnel lens powerhouse gave the maximum power output of $30 \mathrm{~W}$ at $700 \mathrm{~W} / \mathrm{m} 2$ solar intensity and it is reasonable in comparison to the size of Fresnel lens and quantity of steam generated.

- Solar thermal salt would be the better media for steam generation in the heat exchanger. In the present work, a mixture of $\mathrm{KNO} 3$ and $\mathrm{NaNO} 3$ solar salts gave better results compared to the use of the single salt, KNO3.

- Study on heat exchanger indicated that corrosion resistant brass material at the shell side and copper material at the tube side would be a better choice to generate more power and high steam temperature 
- Increase in turbine speed gave more power and it is in line with Fan power law relationship.

\section{References}

1. A. Alvarez, Finite element modelling of a solar collector, Renewable Energies and Power Quality, 6, pp.4-15 (2010).

2. J. Incropera \& D. DeWitt, Fundamentals of Heat and Mass Transfer, 2nd edition New York: John Wiley and Sons (1990).

3. F. Jorge \& O. Armando, Numerical simulation of a trapezoidal cavity, Journal of Renerwable energy, 36, pp.90-96 (2011).

4. P. Kumar, Development of Fresnel powerhouse prototype with thermal energy storage concentrated solar power, International Journal For Technological Research In Engineering .5 (1), pp. 2347-4718 (2014)

5. H. Petcu \& A. Badea, Theoretical and experimental assessment of stationary and dynamic running of one flat plate solar collector, International Journal of Low-Carbon Technologies, 72(2), pp. 48-55 (2010).

6. A. Rebel, Active Solar Collectors and Their Applications. [e-book] Oxford University Press, (1985).

7. I. Soriga \& C. Neaga, Thermal analysis of a linear Fresnel lens solar collector with black body cavity receiver, International Journal of Low-Carbon Technologies, 74 (4) pp. 106-116 (2012).

8. B. Vick, Thermal solar track, American Solar Energy Society Conferences, San Francisco, California, Sunday 6th to Thursday 10th July2014, California:PubM.pp.2-7 (2014).

9. J.A. Duffie, \&W.A.B Eckman, Solar engineering of thermal processes. 2nd edition New York: John Wiley and Sons (1980).

10. M. Rajaee, \& Syed M B G., Experimental measurements of a prototype highconcentration Fresnel lens and sun-tracking method for photovoltaic panel's efficiency enhancement, Journal of Theoretical and Applied Physics, 9(4) pp. 251-259 (2015).

11. R.R Udawant, K.C Mohite \& M.G Takwale, Study on performance of Fresnel lens solar concentrator, International Journal of Energy Engineering, 6(1) pp. 14-22 (2016). 